\title{
Identifying Barriers to the Remix of Translated Open Educational Resources
}

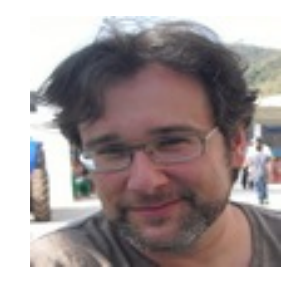

Tel Amiel

UNICAMP, Brazil

\section{Abstract}

Remix is touted as one of the most important practices within the field of open educational resources (OER). But remixing is still not mainstream practice in education and the barriers and limitations to remix are not well known. In this article we discuss the design and development of a print and web-based booklet created to introduce the topic of OER to schoolteachers. The guide, the first of its kind available in Portuguese, was created through the remix and translation of existing resources available in English. Choosing design-as-remix raised a series of concerns related to licensing, attribution, context, and technical standards. In this article we review the concerns related to culture and inequity within the OER movement, followed by the design choices and procedures, and finally the implications of these issues for the open educational resources movement.

Keywords: Open educational resources; remix; translation; culture; instructional design 


\section{Introduction}

The open educational resources (OER) movement has led to a series of initiatives focused on the potential of the exchange, sharing, adaptation, and modification of content. This has lead to exciting new ways to think about how educational content is created and used in formal and non-formal educational settings. At the same time we have come to realize that OER can potentially sustain divides, such as the division between those who traditionally create and those who consume educational resources. Without due attention we face a neo-colonization and one-way flow of content based on the massive amount of content published by those in richer nations. In effect, we cannot expect that the expansion of infrastructures will automatically promote more equitable exchanges in educational content if we do not build systems and capacity so that minority and marginalized groups can effectively contribute (CERI, 2007; Reich, 2011; Reich, Murnane, \&Willett, 2012).

This concern became the basis of the investigation into the design of a resource entitled Open Educational Resources (OER): A guide for teachers written in Portuguese. In order to promote OER and its inherent practices, the guide was developed as an OER itself, using open-source software and distributed with an open license. Moreover, instead of creating a new resource from scratch the publication was assembled from the revision and remix of existing resources.

Below, we briefly discuss the field of OER and the importance of remix, followed by an explanation of the design process while highlighting some of the benefits, barriers, and concerns that came to the fore when creating the booklet. Our goal was of a very practical sort: to design a reference/instructional resource all the while investigating this practice. The question that guided this study was: What design choices and challenges does one face when one decides to create a work through the remix of translated open educational resources?

\section{Open Educational Resources}

The OER movement is often associated with the concept of learning objects (LO), part of a research and development program aimed at creating an ecosystem (both educational and economic) for the development of modular media for education (for a review see Downes, 2001). The two terms are still used by many interchangeably. Much of the difference between the two programs is focused on the concept of openness. According to Wiley (n.d.), "open" means an ability to reuse (unaltered, as is), revise (adapt and modify the content, such as a translation), remix (combine the original content or revisions, creating something novel), and redistribute (share copies of the original, revised or remixed content). These four terms have come to be known as the 4 Rs. The terminology is not yet consolidated and these four terms and others (such as repurpose and adapt) are used differently in diverse contexts and by different authors (see for example Gunn, Woodgate, \&O'Grady, 2005). For our purposes, OER can be defined as 
...teaching, learning and research materials in any medium that reside in the public domain and have been released under an open licence that permits access, use, repurposing, reuse and redistribution by others with no or limited restrictions...The use of open technical standards improves access and reuse potential. OER can include full courses/programmes, course materials, modules, student guides, teaching notes, textbooks, research articles, videos, assessment tools and instruments, interactive materials such as simulations and role plays, databases, software, apps (including mobile apps) and any other educationally useful materials. The term 'OER' is not synonymous with online learning, eLearning or mobile learning. Many OER while shareable in a digital format - are also printable. (UNESCO/ COL, 2011)

\section{Remixing Educational Resources}

The two-tiered level (technical and legal) of openness emphasized above is essential to remix practices. The concept of remix in education is grounded upon the idea that people should have not only greater access but also greater freedoms in what they can do with educational resources. These activities have the potential to take innovative form in more open, commons-based peer production models (Benkler, 2005; Simon \& Vieira, 2008). Educationally one could trace this trend to earlier conceptions of how schooling itself should be structured (Papert, 1980) and the importance of promoting production and creation in fostering media literacy (Erstad, 2008).

There are great barriers to promoting these participatory activities. In a study conducted within higher education Collis and Strijker (2003) indicated that “...there has been little success with bringing instructors close to an actual authoring process: instructors do not have the time, interest, or skills" (p. 5). These concerns are in line with historical problems in the adoption of educational technologies and educational change at all levels of formal schooling (Tyack \& Cuban, 1997).

Existing educational sites and repositories contribute to this concern. Most are focused on the distribution and dissemination of resources and provided little guidance or tools for those who wish to make revisions or remix existing resources. There are notable exceptions, which include open wiki-based sites (such as Wikipedia and Wikieducator) and those that explicitly support remix such as Connexions (CNX, www.cnx.org). In Connexions users can upload resources and construct courses or modules. One can remix existing content in order to create derived versions within the platform. A recent study of CNX by Ochoa (2010) indicates that, among other findings, "A third of the material (34\%) is never reused inside a course and $44 \%$ is only used once. The $22 \%$ remaining is reused between 2 and 8 times" (p. 18). There is an increasing amount of 
content in CNX, but reuse, while practiced, might still be limited. In another study involving CNX, Petrides and colleagues (2008) indicate that in spite of possible technical challenges and a resistance to using third-party content there is evidence that users engage in making modifications to other's content, creating new "versions" of existing modules.

New platforms such as OER Glue (now http://www.opentapestry.org) or Open Author (http://www.oercommons.org/contribute/) can help to break down some of the technical barriers associated with remixing, evident in most of the more popular websharing sites (for a review, see Seneviratne \& Monroy-Hernández, 2010).

While these technical barriers do exist, many difficulties are extra-technical and related to structural changes in organizations, reward and merit systems, competencies (beyond tools), availability of resources, and other concerns that must be addressed concomitantly (Malcolm, 2005; UNESCO/COL, 2011). Promoting participation and activity in OER therefore also means revisiting often forgotten socio-technical concerns in regards to the infrastructures necessary to use, produce, and disseminate resources (for a discussion, see Warschauer, 2002) and the often undermined issues of culture in instructional design (Parrish, 2010).

An increasing number of studies focuses on remix, and there is flourishing research activity in areas such as music (Mizukami \& Lemos, 2008). In education there is “.. still a limited understanding of how to move beyond some of the encumbrancesspecifically with regard to reusing others' content as well as more complex reuse behaviors that lead to new configurations of existing content" (Petrides et al., 2008, p. 352). In this study we describe the design of one such resource created partially through the reuse of third party works. Next we detail the design procedures and some of the challenges and lessons learned in the process.

\section{Method}

A traditional designer of a new resource might survey the field to identify existing resources as a source of inspiration or reference, but copyright limitations or an emphasis on novelty might prevent one from envisioning these as elements to be incorporated beyond citation or reference (J ohnson-Eilola \& Selber, 2007). The OER cycle, on the other hand, begins precisely with the idea that resources can be adapted and adopted.

Our aim was to design, through remix, a booklet for teachers in order to provide an overview of OER. Implicit in the idea of localization and remix is an interpretivist epistemology and a constructivist stance towards the design of educational resources. A resource created through remix and promoted as a "remixable" work is meant to address some of the limitations of traditional instructional design, particularly the need to cater to multiple contexts and learner needs (Amiel, Squires, \& Orey, 2009). 
The audience for the booklet was composed of public school teachers at the K-12 level in Brazil. This is a wide and varied audience to consider, and attending to the needs and anxieties of such a wide group would be problematic. In order to provide context for development, a small group of teachers participated in a seminar focused on OER and were able to informally share their questions and ideas regarding the field. The workcontexts of these teachers, which were known to the designers from research and previous collaborative studies, were used as the scenario for the development of the booklet (Pezzo et al., 2011). Constraints, resources, and possibilities were considered from the standpoint of these scenarios. Working within the limitations and constraints of real activities differs substantially from imagined, prototypical, or generic target groups (for a review of the issues for instructional design, see Amiel, 2011).

At the time we found no existing guides or books in Portuguese focused on explaining the domain of OER, which limited "reuse" in principle. We looked for other openly licensed guides that we could revise. In doing so we found five potentially useful resources from credible sources. Out of these five, two contained a table of contents with very sparse content, and the other three were full-fledged resources.

One was a table of contents created within a UNESCO-led community (http:// oerwiki.iiep.unesco.org/index.php/UNESCO OER Toolkit), and a second was created by the OER-Brazil community (http:// br.wikimedia.org/ wiki/ Recursos educacionais abertos/Cartilha).

The three complete resources were created by Wikieducator (http:// wikieducator.org/ OER_Handbook/ educator version one), J ISC (https://openeducationalresources.pbworks.com/ w/page/24836480/Home), and Curriki (http://tinyurl.com/5r2u8lf), all well-known organizations within the OER movement.

Table 1

Identification of Common Themes in OER Guides

\begin{tabular}{|l|l|l|l|c|c|c|}
\hline Section & Common & OER-Brazil & WikiEducator & UNESCO & J ISC & Curriki \\
\cline { 2 - 7 } & License & CC-BY-SA & CC-BY & $\begin{array}{c}\text { Not } \\
\text { identified }\end{array}$ & CC-BY-SA & CC-BY \\
\hline Introduction & $\begin{array}{l}\text { OER } \\
\text { concepts }\end{array}$ & $\begin{array}{l}\text { OER } \\
\text { concepts }\end{array}$ & $\begin{array}{l}\text { Defining OER } \\
\text { \&OER life } \\
\text { cycle }\end{array}$ & Background & What are OERs? & $\begin{array}{l}\text { OER commons } \\
\text { tutorial (wiki } \\
\text { has no terms of } \\
\text { use, but OER } \\
\text { Commons is CC- }\end{array}$ \\
\hline
\end{tabular}




\begin{tabular}{|c|c|c|c|c|c|c|}
\hline & & & & & & (BY-NC-SA) \\
\hline & Why OER & Why OER & Why OER? & $\begin{array}{l}\text { Benefits of } \\
\text { OER }\end{array}$ & $\begin{array}{l}\text { Why OER? \&An } \\
\text { interesting OER } \\
\text { metaphor (OER } \\
\text { myths) }\end{array}$ & Use: Motivation \\
\hline & Examples & $\begin{array}{l}\text { Finding and } \\
\text { using } \\
\text { resources }\end{array}$ & Find OER & $\begin{array}{l}\text { Example } \\
\text { projects }\end{array}$ & $\begin{array}{l}\text { Overviews \& } \\
\text { guidance }\end{array}$ & $\begin{array}{l}\text { Find/search: } \\
\text { General } \\
\text { repositories }\end{array}$ \\
\hline & $\begin{array}{l}\text { How OER } \\
\text { can help } \\
\text { me }\end{array}$ & Why OER & $\begin{array}{l}\text { Use: } \\
\text { Integrating } \\
\text { OER in } \\
\text { teaching and } \\
\text { learning }\end{array}$ & $\begin{array}{l}\text { Beyond the } \\
\text { classroom }\end{array}$ & $\begin{array}{l}\text { Learning \& } \\
\text { teaching } \\
\text { considerations }\end{array}$ & $\begin{array}{l}\text { Use: Integrating } \\
\text { OER into your } \\
\text { classroom }\end{array}$ \\
\hline $\begin{array}{l}\text { Educational } \\
\text { practice }\end{array}$ & $\begin{array}{l}\text { Finding } \\
\text { OER }\end{array}$ & $\begin{array}{l}\text { Finding and } \\
\text { using } \\
\text { resources }\end{array}$ & Find OER & $\begin{array}{l}\text { Finding and } \\
\text { using OER }\end{array}$ & Finding OERs & Find/search \\
\hline & $\begin{array}{l}\text { How to } \\
\text { create } \\
\text { OER }\end{array}$ & $\begin{array}{l}\text { Creating } \\
\text { and } \\
\text { publishing } \\
\text { OER }\end{array}$ & Compose OER & $\begin{array}{l}\text { Creating and } \\
\text { sharing OER } \\
\text { \& technical } \\
\text { standards } \\
\text { that facilitate } \\
\text { sharing }\end{array}$ & & Create: OER \\
\hline & $\begin{array}{l}\text { Adapting } \\
\text { OER }\end{array}$ & ( & Adapt OER & & $\begin{array}{l}\text { Cultural } \\
\text { considerations }\end{array}$ & Remix \\
\hline & $\begin{array}{l}\text { Using } \\
\text { OER }\end{array}$ & $\begin{array}{l}\text { Finding and } \\
\text { using } \\
\text { resources }\end{array}$ & Use OER & $\begin{array}{l}\text { Finding and } \\
\text { using OER }\end{array}$ & $\begin{array}{l}\text { OER use and } \\
\text { reuse }\end{array}$ & $\begin{array}{l}\text { Use: Integrating } \\
\text { OER into your } \\
\text { classroom }\end{array}$ \\
\hline & $\begin{array}{l}\text { Sharing } \\
\text { OER }\end{array}$ & $\begin{array}{l}\text { Creating } \\
\text { and } \\
\text { publishing } \\
\text { OER }\end{array}$ & Share OER & $\begin{array}{l}\text { Creating and } \\
\text { sharing OER }\end{array}$ & & $\begin{array}{l}\text { Use: Using and } \\
\text { sharing OER }\end{array}$ \\
\hline
\end{tabular}




\begin{tabular}{|c|c|c|c|c|c|c|}
\hline & $\begin{array}{l}\text { OER tools } \\
\text { and } \\
\text { software }\end{array}$ & $\begin{array}{l}\text { OER } \\
\text { software }\end{array}$ & Compose OER & $\begin{array}{l}\text { Software } \\
\text { tools to } \\
\text { create } \\
\text { content }\end{array}$ & & Create: OER \\
\hline & $\begin{array}{l}\text { Accessibil } \\
\text { ity }\end{array}$ & - & $\begin{array}{l}\text { Accessibility } \\
\text { (adapt, use, } \\
\text { share) }\end{array}$ & - & \begin{tabular}{|l} 
Technical \\
accessibility
\end{tabular} & $5^{-}$ \\
\hline \multirow[t]{3}{*}{ Licenses } & Copyright & Rights & $\begin{array}{l}\text { Copyright } \\
\text { clearance \& } \\
\text { copyright } \\
\text { paradox }\end{array}$ & Copyright & Legal aspects & $\begin{array}{l}\text { Licensing: } \\
\text { Objective } 1\end{array}$ \\
\hline & $\begin{array}{l}\text { Creative } \\
\text { Commons }\end{array}$ & $\begin{array}{l}\text { Open } \\
\text { licenses }\end{array}$ & $\begin{array}{l}\text { Creative } \\
\text { Commons }\end{array}$ & $\begin{array}{l}\text { Copyright } \\
\text { alternatives }\end{array}$ & $\begin{array}{l}\text { Intellectual } \\
\text { property rights }\end{array}$ & $\begin{array}{l}\text { Licensing: } \\
\text { Objective } 3 \& \\
\text { fair use }\end{array}$ \\
\hline & $\begin{array}{l}\text { Defining } \\
\text { licenses } \\
\text { for } \\
\text { resources }\end{array}$ & $\begin{array}{l}\text { Choosing } \\
\text { tools for } \\
\text { creation } \\
\text { and } \\
\text { distribution }\end{array}$ & $\begin{array}{l}\text { Adding a } \\
\text { Creative } \\
\text { Commons } \\
\text { license }\end{array}$ & $\begin{array}{l}\text { How to } \\
\text { license } \\
\text { content }\end{array}$ & - & $\begin{array}{l}\text { Licensing: } \\
\text { Objective } 4\end{array}$ \\
\hline
\end{tabular}

First, we began by listing the topics covered by each of these guides through their major headings (Table 1, first phase of the design process). The items in the table of contents provided us with a wide panorama as to the areas that were considered a priority in introducing the field of OER. Second, we filtered these common areas of interest categorizing according to commonalities or themes, a common practice in the analysis of qualitative data. The topics themselves indicate what each author/organization considered relevant to newcomers to the movement, and repeated elements would be considered of most importance. Third, we highlighted elements that were exclusive to each of the guides (Table 2). This step helped us avoid simply following the average. It also helped us in identifying elements we would likely not have considered on our own and which were of potential relevance to our scenario. For example, the J ISC guide included an "OER myths" category that was unique and deemed of interest. Fourth, these elements were then either subsumed under an existing category, considered as a topic on its own merit, or ignored due to a misalignment with our scope and objectives (such as "Management" under JISC). We also benefited from the regional topics included in the OER-Brazil guide. Issues related to access, national projects, and 
particularities of Brazilian legislation were important to our audience and were included.

Table 2

Exclusive Topics from each Guide

\begin{tabular}{|l|l|l|l|l|}
\hline OER-Brazil & WikiEducator & \multicolumn{1}{|c|}{ Unesco } & J ISC & Curriki \\
\hline $\begin{array}{l}\text { Barriers and } \\
\text { incentives }\end{array}$ & $\begin{array}{l}\text { Copyright } \\
\text { paradox }\end{array}$ & $\begin{array}{l}\text { How should it be } \\
\text { hosted? }\end{array}$ & Management & Fair use \\
$\begin{array}{l}\text { The } \\
\text { question of } \\
\text { access }\end{array}$ & OER life cycle & $\begin{array}{l}\text { Technical } \\
\text { standards that } \\
\text { facilitate sharing }\end{array}$ & $\begin{array}{l}\text { Quality } \\
\text { considerations }\end{array}$ & \\
$\begin{array}{l}\text { National } \\
\text { projects }\end{array}$ & OER & $\begin{array}{l}\text { Social learning } \\
\text { and networking } \\
\text { tools }\end{array}$ & Sustainability & \\
$\begin{array}{l}\text { Brazilian } \\
\text { laws and } \\
\text { educational } \\
\text { policies }\end{array}$ & & $\begin{array}{l}\text { Overcoming } \\
\text { barriers and } \\
\text { finding enablers }\end{array}$ & \\
\hline
\end{tabular}

Fifth, we considered elements that were not included in any of the guides but were thought to be of importance because of our working scenarios. These steps provided the initial framework for the booklet and helped us identify what were considered imperative elements (commonalities), important themes (unique), and other relevant topics (inexistent).

Once the categories were created, the relevant content from each existing resource was examined. Sections of each work were pasted under the appropriate heading. Our goal was to benefit as much as possible from the existing resources, so we aimed first and foremost to make use of the existing works. Once the most appropriate texts were selected we followed a six-step process in identifying what to do with each contribution:

1. in complete form attempting to maintain the original meaning and context (revision);

2. adapting language to reflect local meaning and needs (revision/remix); 
3. modifying substantially to the point of departing from the original source (remix);

4. only as a source of inspiration, demonstrating a need to create content based on the principles and ideas but not borrowing directly from the source itself (reference);

5. identifying instead other, more compatible resources (search);

6. developing entirely new content when none was available (create).

We found that using resources in complete form was not the norm. As we moved from step 1 through 6 for each section we identified a series of design choices and concerns, which we highlight below.

\section{Results}

\section{Licenses}

When remixing resources a series of considerations have to take place, which are not necessarily at the forefront in a traditional process of design. First off, one needs to be sure to select resources with more open licenses. The three sites that were selected for remixing did not have the same license for their materials (see Table 1). Licensing imposes a series of benefits but also challenges for remix. Often resources using more open licenses incorporate or refer to media that are made available using a more restrictive license. For example, the CC-BY Curriki site made reference to an OER Commons page that upon inspection was deemed to be a CC-BY-NC-SA licensed resource. The complexities, costs, and time-constraints in analyzing license compatibility are often undermined (for an example, see MIT OCW, s.d.), and much debate still takes place regarding the risks and benefits of choosing different licenses (see for example, the discussion surrounding "non-commercial" in Klimpel, 2012). Choosing a more restrictively licensed resources will limit the openness of the final work and its attractiveness to future remix.

But what are the possibilities when more strictly licensed resources must be included in the final product? In the academic tradition making partial use of the work of others is generally protected by copyright exceptions and limitations or fair use clauses. Quoting and referencing is a practice essential to the progress and permanence of science and culture (Lessig, 2004). But examining this task from the lens of remix rather than quoting can complicate the process of determining the final document license. For example, within the framework of Creative Commons, remixing a resource licensed with a CC-BY-SA license limits the new resource to start from this same minimum (CC-BYSA). But within academic work, quoting a block of text from an article demands only 
that attribution to the original author be made. This is regular practice in academic writing and in literature where authors liberally cite blocks of text, phrases, and sections in order to compose their own work and publish results.

In the process of designing the booklet, an academic and free (cost) publication, we translated sections of other documents in order to include them in the final work. Some of these resources were more restrictively licensed, but our final choice for publication of the translated and adapted resource was a more open, CC-BY license. The use of "incompatible content" is a major problem for the practice of remix, even when exceptions and limitations (which vary from country to country) might apply (ccLearn, 2009). This is a legal concern, but also a cultural clash between a more liberal consolidated social practice (in this case, academic) and the established and often confusing regulatory sphere (Mizukami \& Lemos, 2008).

These are not trivial decisions and may lead certain designers of resources to produce from scratch rather than remix in order to avoid possible legal conflicts or takedown notices (ccLearn, 2009). Sites are also malleable and licenses often change without a clear history or notice to users. These complications, common within the practice of remix, led to two design decisions. First, we opted to prioritize sources with a more open (CC-BY) license and only sparsely made use of other works in order to avoid possible conflicts. Second, this also impacted the design of the resources itself. Faced with these concerns ourselves, we found it imperative to include a license compatibility chart in our teacher guide in order to assist our readers in navigating the complexity of license compatibility.

\section{Attribution}

Concerns over licensing are further complicated when dealing with revisions to content. The process of translation-as-revision is a case in point and can serve as an example. As Coracini (2007) reminds us, translation is based on active engagement, not a mechanical process. In this sense the translator must identify what is meant rather than what is being said. This involves the persona of the translator, the context in which the text will be read, and many other often-implicit considerations. In revising text to be included in the booklet we struggled to remain faithful to the original meaning while attempting to conform to the audience and context where the final product would be used. In doing so, the final revised product is often quite different than the original text. In this case, should one attribute the result to the original authors? This is a doubleedged sword. On the one hand, one might risk not providing credit to those who created the text; on the other, one might misleadingly credit the original author for something he or she might not have intended to say. When remixing and revising OER in the same language, one could (optimistically) assume that the reader will have access to the original source and will be able to judge the quality of the attribution. This appropriation is particularly delicate when one considers that the final audience usually will not be able to compare the translated to the original version due to language 
barriers. The designer must therefore take extra care in describing what attribution means in each case.

In effect, decisions regarding attribution are expanded and take considerable effort in OER related practices. We opted for attributing every substantial portion of text that was revised as a footnote. When the revision was judged to be relatively faithful to the original and the text was short, a simple reference was made as would be done in traditional academic writing. When substantial changes occurred a mention was made that the revision was only based on or inspired by the original work, with further descriptive commentary when appropriate.

There is shifting ground in how people identify attribution, in line with changing conceptions of authorship. Its implications go beyond the realm of formal education as the practice of remix sustains a principal component of digital culture, what Deuze (2006) approaches through the concept of bricolage:

Most scholars in media and cultural studies invoke bricolage when describing the remixing, reconstructing, and reusing of separate artifacts, actions, ideas, signs, symbols, and styles in order to create new insights or meanings. Originality, or a modernist emphasis on "first things" as an emblem of quality, is thrown out the window in favor of an attitude that prefers an assemblage and tweaking of multiple good copies over a single bad original. (p. 70)

There is evidence that machine-attribution (linking) is not equated by many to be similar to descriptive human-recognition or credit (Monroy-Hernández, Hill, GonzalezRivero, \& boyd, 2011). There is perhaps greater technical and human need for recognizing and describing the quality of the attribution itself. The complexities of design-as-remix, particularly when involving translation, further support the need for more contextualized credit in order to inform the reader in his or her native language.

\section{Language}

Revision also involves a substantial amount of thought into the process of localization. In the case of revision-as-translation, the linguistic concern is of primary importance. An often-ignored barrier to remix and revision is the English-language and western bias of the Internet and particularly OER. In a recent review of the world-wide OER landscape, West and Victor (2011) suggest that one of the most important challenges in the field of OER is the question of language and propose that "technologies that support OER need to support multiple languages and alphabets or scripts" (p. 35). There is a need to foment the production of local knowledge and indigenous ways of knowing in order to foster adequate learning opportunities. Importantly, the 2012 Paris Declaration on OER asks governments to 
Encourage the development and adaptation of OER in a variety of languages and cultural contexts. Favour the production and use of OER in local languages and diverse cultural contexts to ensure their relevance and accessibility. Intergovernmental organisations should encourage the sharing of OER across languages and cultures, respecting indigenous knowledge and rights. (UNESCO, 2012)

The process of remix is usually associated with four steps: finding, relating, creating, and sharing resources (see Shneiderman, 2002). We have found that linguistic concerns permeate each of these steps and, consequently, one's ability to revise and remix. Finding resources in Portuguese is a much more restrictive business than finding those in other languages (Pimienta, Prado, \& Blanco, 2009). Many of the online portals, which contain more openly licensed resources either do not have alternative language interfaces or metadata, which impacts both finding and sharing resources in these sites. Connecting and creating resources depends on the availability of tools that have interfaces in local languages, which is not the case for much software. These are important barriers when considering who is remixing and the limitations a wide audience has in engaging in OER-related practices.

\section{Context}

When presenting OER development and use, many of the restrictions derived from our working scenario came to the forefront. In many cases, the source guides assumed a reader with substantial access to computer-based resources. Our context of work included a computer laboratory that had been closed for three months, limited printing and photocopying in school, and students with limited access to computers at home. At the same time, students had limited access to internet cafés and teachers had easy access to computers at home. These limitations prompted considerable revision to the materials provided in the original texts.

References were made to software available in school computers whether open source or not, though priority was given to explaining the relationship between free and opensource software and OER. While teachers do not have the autonomy to install software in the computers available in their schools they do so in their own homes. Because of these limitations, references to "creating resources" were often made within the scenario of a schoolteacher working at home at his or her own computer. References to OER portals and digital libraries were also adapted to focus on Portuguese-language sites, even though there were few particularly good examples available at the time (Rossini, 2010). While better and more sophisticated examples and references were available in English our working scenario mandated that different choices be made.

If one seriously attends to these contextual elements, introspection in the process of design necessarily leads to a constant process of revision based on cultural concerns 
(Thomas et al., 2002). Every time a unique group with unique characteristics is assembled in a learning situation revision takes place though one might not recognize this practice (Amiel, 2011). A resource simply being reused might be an indication of time or financial constraints or a poor design decision. If it is reused as part of a larger set of resources or different practices than originally intended then it is clearly part of a remix. We contend that once a resource travels from its initial design context, "reuse" necessarily implies "revision". Reuse is perhaps reminiscent of the rhetoric around learning objects as they were presented as blocks of media that could be reused and assembled for different contexts, a metaphor that did not hold in practice (Fulantelli et al., 2008; Gunn et al., 2005).

Considering the context and scenarios of use can help locate socio-technical impediments to active participation and remix activities (see Kling, 2000). When access to resources is limited, the knowledge and ability to make use of alternative software is curbed, and/or linguistic barriers are at play, one can swiftly understand reasons for making use of "ready-made" (legally or illegally) resources rather than remixing open resources.

\section{Technical}

The use of more open licenses is considered a necessary condition to define a resource as OER. An important concomitant step is the use of open standards and formats. Making the original source file available in an open format greatly increases the potential for revision and remix of existing materials. Though one can always attempt to contact the original authors in order to ask for a source file, this is an added burden similar to having to request permission to make use of copyrighted material. Providing an easily editable file is not only a facilitating process, it is also a recognition that others too can create and produce.

Within the OER movement, reducing technical barriers is only an emerging practice and has not received the same attention as open licensing. Open formats encourage and enhance the ability of individuals to openly translate and share resources. One such example is the Bound by Law comic book which includes the resource in multiple formats including individual book pages and images without text to facilitate translation (Aoki, Boyle, \& Jenkins, 2006). Other emerging tools that facilitate the process of revision-as-translation of web-based video include Universal Subtitles (http:// www.universalsubtitles.org).

These concerns are directly related to the degree of openness a designer is willing to provide, and function in tandem with the choices associated with selecting an open license:

It is important to recognise that 'openness' is not a dichotomous concept; rather, there is a continuum of openness. Designers of OERs should decide early on 
whether they wish to facilitate reuse and redistribution only, or if they also want to enable revising and remixing. Those who wish to facilitate reuse and remix of OERs should license their works accordingly. In addition, technical aspects of OERs will affect how 'open' they really are. Creators of OERs who wish to promote revising and remixing should ensure that OERs are designed in such a way that users will have access to editing tools, that the tools needed will not require a prohibitive level of expertise, and that the OERs are meaningfully editable and self-sourced. (Hilton III, Wiley, Stein, \&J ohnson, 2010, p.43)

In other words, the legal and technical choices for OER work in collaboration and in tension. Selecting a very open license (such as CC-BY) implies a willingness to make the resource "open", which can effectively be limited by the technical standards used to provide the resource. If the intention of the author is indeed to support remix then there is little reason not to include the source files or data available. Moreover, in alignment with the concerns over linguistic barriers, providing files in open formats substantially enhances the possibility that minority groups can adequately remix resources through free and open software. In our case, this impacted two design decisions. First, opensource software and open formats were used to create the booklet and make it available. The booklet can be accessed as plain text (in an open wiki), as PDF (formatted, an open standard), and in its original, editable format (formatted in Scribus, open-source software). Second, original graphics were provided in open standards but also with their original source files available for download.

\section{Conclusions}

This study aimed to contribute to the understanding of some of the barriers designers may face in remixing open educational resources, particularly through the process of translation. Though OER opens the possibility of revision and remix, one should be aware of the many efforts and decisions associated with such practices. Issues of licensing led us to make complex choices in defining what to use and how to remix resources. Attribution can become a complex task as issues of authorship are on shifting ground. Issues of language and context make the straightforward reuse of resources difficult; we found revision to be the norm. Finally, we have found that technical issues, particularly concerning the use of open standards and editable sources, to be of the essence. Without attention to these technical concerns the collaborative and participatory practices of remix can be cumbersome and problematic.

Two limitations of this study should be acknowledged. First, no comparisons were made between the efficiency or quality of a "remix" versus a "design-from-scratch" strategy. 
Indeed, this article is focused on the process of design and remix concerns, and its scope does not permit us to expand on the theoretical contrasts between traditional instructional (systems) design and design-as-remix models. Second, this report does not discuss the impact or use of the resource; this is left to future study.

Still one can contend that remixing can be conducive to creating a better product. This stems essentially from "borrowing" from the expertise and know-how of other colleagues and reaping the fruits of their design reflections, which is implicit in their final products. The decisions that go into the design (content, examples, structure) are implicit testimony to the design process. When one engages in remix, one is borrowing not only the content, but also the expertise and the thought process that is embedded in design.

There is an effective need to promote the sorts of ecosystems that will allow local groups to create, remix, and share resources. There is still great disparity in the amount and quality of resources and tools available to different peoples around the world. The discussions around inequity, reminiscent of the digital divide debate, will continue to afflict us. Participatory practices hold great promise and should be further promoted. These practices can not only provide access to an increasing number of local resources but, importantly, incentivize investigation on what constitutes knowledge, who produces knowledge, and how it is constructed - discussions that go beyond financial and time costs associated with translation and localization processes (for a discussion, see Banks, 2004; Wanderley, 2010).

As valuable as it may be, remixing opens up a set of legal, technical, linguistic, and contextual issues that if ignored may oversimplify and discourage remixing activities and the benefits they bring about. Open educational resources provide us with new and exciting opportunities but also present unique challenges that must be recognized. Disseminating design experiences can help us understand barriers and find ways to promote more open practices.

\section{Acknowledgement}

The author would like to thank Dr. Michael Orey for reviewing a working version of this article and Elayne Morais for her design work. 


\section{References}

Agostinho, S., Meek, J., \& Herrington, J. (2005). Design methodology for the implementation and evaluation of a scenario-based online learning environment. J ournal of Interactive Learning Research, 16(3), 229-242.

Amiel, T. (2011). The localization of open educational resources: The role of culture, user and activity. Paper presented at the International Symposium on Open Educational Resources, Logan, Utah. Retrieved from http:// educacaoaberta.org/

Amiel, T., Squires, J., \& Orey, M. (2009). Four strategies for designing instruction for diverse cultures. Educational Technology, 49(6), 28-34.

Amiel, T., \& West, R. (Eds.). (2011). Proceedings of the 1st Symposium on Open Educational Resources (1 $1^{\text {st }}$ ed.). Logan, Utah. Retrieved from http:// educacaoaberta.org/

Aoki, K., Boyle, J., \& Jenkins, J. (2006). Bound by law? Retrieved from http:// web.law.duke.edu/cspd/comics/digital.php

Banks, J. A. (2004). Multicultural education: Historical development, dimensions, and practice. In J . A. Banks \& C. A. M. Banks (Eds.), Handbook of research on multicultural education ( $2^{\text {nd }}$ ed., pp. 3-29). San Francisco, CA: John Wiley \& Sons.

Benkler, Y. (2005). Common wisdom: Peer production of educational materials. Logan, Utah: Center for Open and Sustainable Learning at the Utah State University.

ccLearn. (2009). Otherwise open: Managing incompatible content within open educational resources.

CERI. (2007). Giving knowledge for free: The emergence of open educational resources. Paris: OECD.

Collis, B., \& Strijker, A. (2003). Re-usable learning objects in context. International J ournal on E-learning(October-December), 5-16.

Coracini, M. J. (2007). A Celebração do Outro: Arquivo, memória e identidade de línguas, (materna e estrangeira), plurilinguismo e tradução. Campinas: Mercado das Letras.

Deuze, M. (2006). Participation, remediation, bricolage: Considering principal components of a digital culture. Information Society, 22, 63-75. doi: 10.1080/01972240600567170 
Downes, S. (2001). Learning objects: Resources for distance education worldwide. International Review of Research in Open and Distance Learning, J uly.

Erstad, O. (2008). Trajectories of remixing: Digital literacies, media production, and schooling. In C. Lankshear \& M. Knobel (Eds.), Digital literacies (pp. 177-202). New York: Peter Lang Publishing.

Fulantelli, G., Gentile, M., Taibi, D., \& Allegra, M. (2008). The open learning object model to promote open educational resources. J ournal of Interactive Media in Education(May), 1-11.

Gunn, C., Woodgate, S., \& O'Grady, W. (2005). Repurposing learning objects: A sustainable alternative? ALT-J : Research in Learning Technology, 13(3), 189200.

Hilton III, J., Wiley, D., Stein, J ., \& J ohnson, A. (2010). The four 'R's of openness and ALMS analysis: Frameworks for open educational resources. Open Learning: The Journal of Open, Distance and e-Learning, 25(1), 37-44. doi: 10.1080/02680510903482132

Johnson-Eilola, J., \& Selber, S. A. (2007). Plagiarism, originality, assemblage. Computers and Composition, 24(4), 375-403. doi: 10.1016/j.compcom.2007.08.003

Klimpel, P. (2012). Free knowledge based on creative commons licenses consequences, risks and side-effects of the license module "non-commercial use only - NC." Berlin: Wikimedia Germany/ iRights.info.

Kling, R. (2000). Learning about information technologies and social change: The contribution of social informatics. The Information Society, 16, 217-232.

Lessig, L. (2004). Free culture. New York: Penguin Books.

Malcolm, M. (2005). The exercise of the object: Issues in resource reusability and reuse. British J ournal of Educational Technology, 36(1), 33-41.

MIT OCW. (s.d.). Why donate? Retrieved from http://ocw.mit.edu/donate/ whydonate/

Mizukami, P. N., \& Lemos, R. (2008). Culture: The emergence of open business. In L. Shaver (Ed.), Access to knowledge in Brazil: New research on intellectual property, innovation and development (pp. 25-63). New Haven, CT: Yale Law School.

Monroy-Hernández, A., Hill, B. M., Gonzalez-Rivero, J ., \& boyd, d. (2011). Computers can't give credit: How automatic attribution falls short in an online remixing 
community. Paper presented at the Annual Conference on Human Factors in Computing Systems, Vancouver, BC.

Ochoa, X. (2010). Connexions: A social and succesful anomaly among learning object repositories. J ournal of Emerging Technologies in Web Inteligence, 2(1), 22.

OPAL (2011). Guidelines for open educational practices in organizations. Retrieved from http:// www.oer-quality.org/ wp-content/ uploads/2011/03/OPAL-OEPguidelines.pdf

Papert, S. (1980). Mindstorms: Children, computers, and powerful ideas. New York, NY: Basic Books.

Parrish, P., \& Linder-VanBerschot, J. (2010). Cultural dimensions of learning: Addressing the challenges of multicultural instruction. The International Review of Research in Open and Distance Learning, 11(2).

Petrides, L., Nguyen, L., Kargliani, A., \&J imes, C. (2008). Open educational resources: Inquiring into author reuse behaviors. Paper presented at the 3rd European conference on Technology Enhanced Learning: Times of Convergence: Technologies Across Learning Contexts, Maastricht, The Netherlands.

Pezzo, T., Amorim, S., \& Amiel, T. (2011). Metodologia participativa para o desenvolvimento de recursos educacionais abertos para sociologia. ENESEB. Retrieved from http:/ / www.educacaoaberta.org/

Pimienta, D., Prado, D., \& Blanco, A. l. (2009). Twelve years of measuring linguistic diversity in the Internet: Balance and perspectives. Paris: UNESCO.

Reich, J. (2011). Will free benefit the rich? Retrieved from http:// www.edtechresearcher.com/ 2011/ 11/ will-free-benefit-the-rich/

Reich, J ., Murnane, R., \& Willett, J . (2012). The state of wiki usage in U.S. K- 12 schools. Educational Researcher, 41(1), 7-15. doi: 10.3102/0013189x11427083

Rossini, C. (2010). Green-Paper: The state and challenges of OER in Brazil: From readers to writers? (p. 75). Boston: Harvard University.

Seneviratne, O., \& Monroy-Hernández, A. (2010). Remix culture on the web: A survey of content reuse on different user-generated content websites. Paper presented at WebSci10: Extending the Frontiers of Society, Raleigh, NC.

Shneiderman, B. (2002). Leonardo's laptop. Cambridge, MA: MIT Press.

Simon, I., \& Vieira, M. S. (2008). O rossio não-rival Além das redes de colaboração: Internet, diversidade cultural e tecnologias do poder (pp. 15-30). Salvador, Bahia: UFBA. 
Thomas, M., Mitchell, M., \& Joseph, R. (2002). The third dimension of ADDIE: A cultural embrace. Techtrends, 46(2), 40-45.

Tyack, D., \& Cuban, L. (1997). Tinkering toward utopia: A century of public school reform. Boston, MA: Harvard University Press.

UNESCO. (2012). 2012 Paris OER Declaration. Retrieved from http:// www.unesco.org/new/ fileadmin/MULTIMEDIA/HQ/CI/CI/pdf/Events $\angle$ English Paris OER Declaration.pdf

UNESCO/COL. (2011). Guidelines for open educational resources (OER) in higher education. Vancouver: COL.

Wanderley, C. M. (2010). Bibliotecas digitais multilingues: uma proposta inclusiva. In G.N. Cyranek (Ed.), Greenstone: Un software libre de código abierto para la construccíon de bibliotecas digitales: Experiências en América Latina y el Caribe (pp. 45-74). Montevideo: UNESCO.

Warschauer, M. (2002). Demystifying the digital divide. Scientific American, August, 42-48.

West, P. G., \& Victor, L. (2011). Background and action paper on OER. The William and Flora Hewlett Foundation.

Wiley, D. (n.d.). Defining the "open" in open content. Retrieved from http:// opencontent.org/definition/

\section{Athabasca University $\mathbf{I}$}

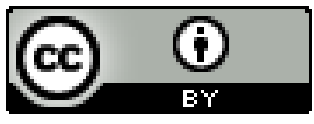

